\title{
MÁQUINA DE EDUCAR, MÁQUINA DE PREVENIR: O MODELO ESCOLAR OCIDENTAL E A EMERGÊNCIA DA PREVENÇÃO ÀS DROGAS NA EDUCAÇÃO
}

\author{
Tiago Ribeiro*
}

\begin{abstract}
RESUMO: O texto aborda aspectos de como a prevenção ao uso de drogas tornou-se um assunto educacional. O objetivo é entender como o modelo de educação escolar operou enquanto condição de possibilidade para que, diante do aumento do uso de drogas, e da percepção desse fenômeno como um "problema social", a prevenção emergisse, nos tempos e espaços escolares, como uma tecnologia voltada ao governamento da população e à gestão dos riscos sociais. Entende-se que a inclusão da prevenção às drogas como temática escolar faz parte do aprofundamento de uma racionalidade política voltada à gestão dos riscos sociais e examina-se os anais de um evento que, realizado no ano de 1970, propôs uma série de medidas de combate às drogas, dentre as quais se destaca a abordagem escolar de tal tema. Examina-se enunciados circulantes nesse documento e conclui-se haver um processo histórico de instrumentalização da educação para fins políticos de controle social.
\end{abstract}

Palavras-chave: Educação. Prevenção ao uso de drogas. Modelo escolar. Governamentalidade.

\section{EDUCATION MACHINE, A PREVENTING MACHINE:}

THE WESTERN SCHOOL MODEL AND THE EMERGENCE OF

\section{DRUG PREVENTION IN EDUCATION}

ABSTRACT: The text addresses aspects of how drug prevention has become an educational issue. The aim is to understand how the schooling model has worked as a means for drug prevention to emerge in the school times and spaces as a technology targeted to govern the population and manage social risks, while drug use was increasing and this phenomenon was conceived as a "social problem". As we see it, including drug prevention as a school subject is part of the deepening of a political rationality towards social risk management. Therefore we examined the annals of a 1970's event which proposed several measures to prevent drugs, including the school approach

* Doutorando em Educação na Universidade do Vale dos Sinos (Unisinos) e técnico em Assuntos Educacionais no Instituto de Filosofia e Ciências Humanas, da Universidade Federal do Rio Grande do Sul (UFGRS). E-mail: tiagomribeiro@gmail.com 
to this issue. We analyzed the operative statements in this document, and concluded that there is a historic process of guiding education for political purposes of social control.

Key words: Education. Preventing drug use. School model. Governmentality.

\author{
MACHINE D'ÉDUCATION, MACHINE DE PRÉVENTION: \\ LE MODÈLE SCOLAIRE OCCIDENTAL ET LE CAS D'URGENCE DE LA \\ PRÉVENTION AUX MÉDICAMENTS DANS L'ENSEIGNEMENT
}

\begin{abstract}
RÉSUMÉ: Le texte relève les aspects de comment la prévention à l'utilisation de médicaments est devenue un sujet de l'enseignement. L'objectif est de comprendre comment le modèle d'enseignement scolaire a été établi comme la condition de possibilité pour l'augmentation de l'utilisation de médicaments et de la perception de ce phénomène comme "un problème social". De cette façon, la prévention apparaît dans un contexte scolaire, comme une technologie dirigée à gouverner la population et à la gestion des risques sociaux. On comprend que l'inclusion de la prévention aux médicaments comme thématique scolaire fait partie de l'approfondissement d'une rationalité politique concernant la gestion des risques sociaux. Ensuite, on examine les annales d'un événement réalisé en 1970, qui propose une série de mesures de combat aux drogues, parmi lesquelles se détache l'abordage scolaire d'un tel thème. Enfin, des déclarations dans ce document ont été examinées et on conclue avoir un processus historique d'instrumentalisation de l'enseignement dans un but politique de contrôle social.
\end{abstract}

Mots-clés: Enseignement. Prévention à l'utilisation de médicaments. Modèle scolaire. Gouvernamentalité.

$\mathrm{E}$ ste artigo é inteiramente dedicado à compreensão de como as características e funcionalidades do modelo de educação que se tornou historicamente dominante nas sociedades ocidentais contemporâneas puderam operar como condições de possibilidade para que, na década de 70 do século XX, a prevenção ao uso de drogas fosse proposta como conteúdo a ser abordado nas salas de aula brasileiras. Trata-se de compreender como o falar em prevenção às drogas nos tempos e espaços escolares, hoje, relaciona-se diretamente com processos históricos mais remotos, bem como com certa forma de gerir a população e de pensar a educação como ferramenta de prevenção aos riscos sociais. A escola, nessa perspectiva, constitui uma maquinaria extremamente funcional no sentido de constituir sujeitos adequados a projetos políticos específicos. Educar e prevenir amalgamam-se, assim, na gestação de um espaço destinado à intervenção técnica sobre o pensamento, sobre o sentimento, claro, mas especial e profundamente sobre o querer. A esse espaço chamaremos escola.

Nas próximas páginas serão confrontadas as descrições e interpretações feitas por pesquisadores da história da instituição escolar com enunciados pinçados do Fórum de Debates sobre o Uso e o Tráfico de Substâncias Tóxicas ou que Causam 
Dependência Física ou Psíquica, evento pioneiro que, realizado em Porto Alegre no ano de $1970,{ }^{1}$ caracterizou-se pela defesa da adoção da prevenção como tática prioritária no enfrentamento da questão do tráfico e do uso de drogas no Brasil. O objetivo dessa confrontação é compreender como traços estruturais da forma de organização da educação adotada no Ocidente tornaram possível o pensamento segundo o qual a prevenção ao uso de drogas deveria constituir uma nova demanda aos professores e aos sistemas de ensino.

\section{Educar e prevenir: escolarizar}

Ao longo do século XX a escola firmou-se como espaço oficial de educação nas sociedades ocidentais. A escolarização massiva constitui parte importante do projeto do Estado-nação para equipar os indivíduos de técnicas que os assujeitem, tornando-os aptos e dispostos para exercerem funções profissionais adequadas às dinâmicas sociais e econômicas da contemporaneidade (Ó, 2008).

A própria estrutura da maquinaria escolar, tal como descrita e analisada por Foucault (1988), é instituída tendo em vista prioritariamente a consecução desses objetivos ligados ao assujeitamento. Fazer de todos um só, eis o princípio do governamento ${ }^{2}$ que se exerce na escola: tomar uma multiplicidade de corpos, de gestos, de posturas, de interesses, de valores, de condutas, de energias dispersas e homogeneizá-la ao ponto de produzir individualidades que, atomizadas, adotem padrões minimamente previsíveis e genéricos de comportamento, facilitando a identificação e correção de anomalias. Para que tal intento seja viável, é necessária a separação dos jovens, no máximo nível possível, do mundo exterior, não institucionalizado e, portanto, suscetível de incutir-lhes outros padrões comportamentais. Como aponta Jorge do Ó (2008), a história da escola é uma história de sobreposição do ser ao saber, de conexão do indivíduo à verdade que o assujeitará, progressivamente, por meio da aquisição de experiências mais do que de conhecimentos. Em tal instituição, e aqui esse raciocínio se refere especialmente à escola pública, de massas, universal, gratuita e obrigatória, a avaliação, em grande medida, centra-se nos comportamentos, pois se trata de civilizar, normalizar, neutralizar a ameaça do distúrbio, da supressão da ordem; no Brasil, historicamente relacionada ao controle das populações pobres, de ex-escravos, vadios e desempregados (CHALHOUB, 1996). A essa lista poderiam ser acrescentados, sem dúvida, no contexto atual, os usuários de drogas, principalmente se estes aliarem a essa categoria de identificação uma ou mais das acima referidas, multiplicando seus estigmas e sua potencialidade como "focos" de perigo.

O uso de drogas é qualificado, no documento que apresenta as metas do Fórum de Debates, como sintoma de "desadaptações psicossociais" (FÓRUM DE DEBATES..., 1971, p. 7) 3 que deveriam ser prevenidas e, se possível, revertidas. 
Para tal intento depositava-se na escola uma grande esperança, vendo-a como um espaço de produção da "adaptação" dos indivíduos ao grupo social. A escola, então, pode ser compreendida como uma instituição estratégica que opera no sentido de tornar o mundo, a vida, os indivíduos e a população objetos governáveis. Esse governamento pode ser entendido como "preventivo" e tem por método e princípio de funcionamento a mesma lógica que dá forma à prevenção ao uso de drogas, a saber, a ação sobre o "eu". Tal ação visa a incutir modos de autoproblematização e autoavaliação na relação dos sujeitos consigo mesmos, tendo por estratégia a multiplicação dos instrumentos de avaliação exteriores ao sujeito e, por objetivo, a instituição da avaliação permanente que, do exterior, moldaria as relações do "eu" consigo.

Varela e Alvarez-Uría (1991) investigam como e por que surgiu a instituição escolar. Apontando para o século XVI como marco da emergência dessa forma particular de institucionalização das relações educativas, os autores, a despeito de reconhecerem as diversas transformações ocorridas nesse modelo institucional, procuram identificar algumas regras de constituição da escola, regras a partir das quais as transformações se tornaram possíveis. Para eles, a escola, como uma das mais importantes instituições da modernidade, teve, desde o princípio, e ainda hoje, o objetivo de produzir uma ordem mental que esteja de acordo com a ordem social (VARELA; ALVAREZ-URÍA, op. cit.). Trata-se, portanto, de uma instituição criada com o intuito de produzir os tipos de pessoa mais adequados à manutenção do funcionamento da sociedade no interior de uma ordem determinada. Ou, ainda, trata-se de uma maquinaria instituída tendo em vista o resguardo e a proliferação de uma configuração particular das relações de poder.

A escola, como espaço fechado no qual os jovens permanecem internados por longas horas, teve no convento seu antecedente histórico modelar: o isolamento a que eram submetidos os noviços mostrou-se bastante produtivo em termos de governamento e constituição de sujeitos. Do mesmo modo, na escola, uma vez isolados, os jovens podem ser mais bem inspecionados, tendo seus comportamentos medidos e refletidos de forma a serem deles extraídos conjuntos de saberes voltados à manutenção da ordem e produção dos comportamentos desejados. Assim, uma série de "ciências sutis de caráter pedagógico [...] tiveram seus começos na gestão e no governo dos jovens" (idem, ibid., p. 34), erigindo-se essa instituição em um dos pilares do projeto moderno, voltado à constituição de uma série de sujeições que tinham por finalidade a formação de sociedades civilizadas, sadias, produtivas e capazes de realizar os ideais de progresso que marcaram os séculos que se seguiram à consolidação dos Estados nacionais modernos.

No Brasil, a emergência de projetos de Nação se intensifica principalmente a partir da Proclamação da República, quando intelectuais, artistas, gestores públicos e elites políticas e econômicas começam a debater intensamente o "caráter" nacional, 
na tentativa de inserir o país no mundo civilizado (ORTIZ, 1986). Nesse projeto, o papel das instituições do Estado, dentre as quais se destaca a escola, é operacionalizar uma série de sujeições necessárias para a construção de uma coletividade coesa e em progresso, produzindo uma unidade político-cultural e tendo por fim o bem-estar de todos, fim que passa necessariamente pela produção de sujeitos úteis e dóceis, capazes de submeter suas paixões à razão, seus corpos ao espírito, sua liberdade à obediência e sua consciência àqueles designados para guiá-la, do pai ao professor, do padre ao patrão, passando pelo médico e, depois, pelos profissionais psi.

Parece ser esse o tipo de racionalidade que anima, também, uma série de enunciações feitas no Fórum de Debates que discutiu, entre um conjunto de temas, os modos de condução das condutas dos usuários de drogas. Como proclama o deputado Octavio Germano na sessão de instalação do evento, "a mais importante luta do ser humano é contra ele próprio: a luta titânica do espírito contra a matéria, da razão contra a natureza selvagem e resistente aos valores transcendentais, revelados e estabelecidos no processo civilizatório" (FÓRUM DE DEBATES..., 1971, p. 19). $\mathrm{Ou}$, na formulação do psiquiatra Clóvis Martins, "a medida pedagógica válida para orientar os jovens é manejar a ansiedade sem recorrer às drogas" (idem, ibid., p. 225). Nas palavras do político e nas do médico, trata-se do mesmo recurso ao autocontrole como ideal a ser alcançado, como recurso a ser pedagogicamente gestado no interior de cada um; ponto de encontro, portanto, de um projeto de Nação, de uma concepção do "eu" difundida por determinados saberes psicomédicos, de uma instrumentalização da educação para fins de governamento, ponto de encontro no qual emerge a prevenção ao uso de drogas na educação.

Como afirma o psicólogo Luiz Antônio Meira, "todo toxicômano tem fortes impulsos internos de autodestruição" (ibid., p. 105), enquanto para o psiquiatra Manoel Albuquerque, "todos os narcóticos são buscados para satisfazer as necessidades básicas do homem: fome, impulsos sexuais, agressividade, libertação da dor e da ansiedade" (ibid., p. 171). O uso dessas substâncias é percebido, portanto, como uma forma de realização ou de alívio de pulsões, de modo que escola e psicoativos encontrar-se-iam, segundo tal racionalidade, em posições absolutamente antípodas em relação às formas de se lidar com as paixões naturais do ser humano. Para que se efetive, então, o governamento, é preciso evitar o consumo de substâncias capazes de prejudicar a interiorização dos controles, processo que encontra na escola um espaço privilegiado para sua consecução. Retomando as palavras do psiquiatra Clóvis Martins, segundo as quais "a medida pedagógica válida para orientar os jovens é manejar a ansiedade sem recorrer às drogas", evidencia-se uma concepção para a qual a vida provoca ansiedades e impulsos diversos, diante dos quais alguns jovens recorrem a drogas. Segundo a racionalidade que institui a prevenção, deve-se desenvolver mecanismos para "manejar" a ansiedade e outros impulsos sem apelar para o 
uso dessas substâncias. Eis a função pedagógica da escola em termos de prevenção: desenvolver, nos sujeitos, os meios, as capacidades, as ferramentas que lhes dão condições de gerir seus impulsos adequadamente, impedindo que se "desviem" do caminho correto que os há de conduzir ao mundo "direito", o mundo do trabalho e da vida ordeira. É por meio de uma ação sobre a interioridade que tal desígnio pode ser alcançado, através da submissão dos indivíduos, desde muito cedo em suas vidas, a regimes de observação, avaliação e descrição constantes, regimes estes que têm por resultado, na escola, a produção de cidadãos.

A institucionalização da escola como lugar e momento da educação dos jovens, da sua formação, ou melhor, da sua instituição como sujeitos daquela sociedade específica e não de outra, é indissociável das estratégias de controle social que foram progressivamente postas em funcionamento pelo Estado moderno. Nesse empreendimento, visto como vital para a sobrevivência do próprio Estado, engajouse uma série de especialistas, portadores de saberes gestados para a produção das verdades em acordo com as quais as massas deveriam ser moralizadas, ajustadas, modeladas, de maneira a potencializarem as forças estatais. É essa racionalidade que faz dos professores e da instituição escolar os operacionalizadores das táticas preventivas. É por esses sujeitos e por essa instituição que devem passar os fluxos de poder destinados à condução das condutas dos jovens, no que se refere a seus prazeres e aos usos de seus corpos e mentes. Hábitos de higiene, educação sexual, prevenção ao uso de drogas... Mais do que espaço de inculcação de conhecimentos, trata-se de uma instituição produzida para a inculcação de comportamentos. Assim, "emerge, pois, a escola fundamentalmente como um novo espaço de tratamento moral" (VARELA; ALVAREZ-URÍA, 1991, p. 50), um verdadeiro instrumento de gestão política instituído para atuar sobre a vontade dos sujeitos, na frente de batalha que o Estado, governamentalizando-se, ${ }^{4}$ constitui a fim de gerenciar a vida da população.

Seguindo essa linha de raciocínio, trata-se, então, de romper com as perspectivas que projetam sobre a educação, mais precisamente sobre a escolarização, uma aura quase mágica, entendendo-a como um tempo e espaço destinados à emancipação do sujeito, a sua conscientização de si e do mundo, a sua humanização etc. A perspectiva aqui adotada identifica nas relações educativas - e especialmente na progressiva escolarização obrigatória e universal das sociedades ocidentais - um instrumento cuja gênese pode ser encontrada nos projetos de civilização e governamento das massas, acentuados principalmente a partir do século XIX. Esses projetos logo identificaram uma convergência entre controle político e controle da educação, de modo que, desde então e até hoje, a lógica que rege a instituição escolar, o tipo de formação nela dispensado, os conteúdos nela ensinados, os valores por ela encarnados, tudo isso passou a constituir cada vez mais um objeto de disputa, justamente por essa percepção da capacidade desse instrumento de moldar a alma das 
gerações futuras, decidindo o próprio futuro da sociedade. Desse modo, pode-se compreender a educação universal e obrigatória que tem lugar na escola como uma arma capaz de neutralizar perigos sociais, ameaças à ordem e à configuração mais ou menos estável das relações de poder. Tem-se, aqui, portanto, a própria lógica da maquinaria escolar como condição de possibilidade para a emergência da prevenção às drogas na educação: é a escola como espaço de civilização que faz dela, também e imediatamente, espaço de prevenção de comportamentos que contradizem ou colocam em risco a ordem social que erige o progresso (ou, em termos mais contemporâneos e menos "fora de moda", o desenvolvimento) como sua principal meta e seu primordial valor.

É, portanto, no entendimento do Estado como tutor moral da população que aqui se compreende a entrada da prevenção ao uso de drogas no rol de atribuições de profissionais da educação e dos sistemas de ensino. Contudo, e aí a escola assume centralidade em tal empreendimento, "para engendrar sujeitos dóceis, úteis e maleáveis, é necessário atuar preferentemente durante sua tenra infância, já que é quando os maus hábitos ainda não estão arraigados e a educação moral tem mais possibilidades de deitar fundas raízes" (VARELA; ALVAREZ-URÍA, op. cit., p. 211). O Estado se encarrega, então, da implementação de iniciativas de "ortopedia moral", no interior das quais a prevenção ao uso de substâncias psicoativas encontra espaço privilegiado. Nas palavras do representante do Ministério da Justiça no Fórum de Debates, Leonardo Grecco, "este problema deve merecer a atenção de todos que estudam o uso e o tráfico de drogas, porque evidentemente está se abrindo uma frente de corrupção de costumes, de corrupção da formação moral e intelectual da juventude, o que é muito perigoso para o futuro do país" (FÓRUM DE DEBATES..., 1971, p. 162).

Ora, "os fins educativos estão [...] estruturalmente associados a dinâmicas sociais tão diversas como as do ajustamento social, do castigo, da produtividade, da vitória" (Ó, 2003, p. 104), de modo que ocupa um lugar prioritário na escola, desde sua gênese, o desenvolvimento de um aparato destinado ao "treino moral". Sendo assim, a regulação moral, admitida pelos participantes do Fórum de Debates como objetivo das políticas a serem adotadas no Brasil em relação ao uso de drogas, vem ao encontro dos históricos objetivos da instituição escolar, que tem por desígnio tornar cada aluno capaz de controlar seus impulsos, aprendendo a classificá-los como bons e maus, normais e anormais. Essa ênfase da escola na produção do autocontrole, para Ó (2003), teve no cristianismo uma procedência e tende a produzir uma espécie de hiperconsciência que institui o indivíduo autorreflexivo, capaz de governar suas emoções e prazeres. A escola moderna perpetua, portanto, desde sua gênese, uma moral próxima ao ascetismo, constituindo, também aí, a instituição ideal para a produção de vontades abstêmias em relação aos prazeres perigosos representados 
pelos psicoativos. Essa moral, no entanto, laicizada e racionalizada, tem por referência os fins estatais de produção e gestão de uma população saudável e economicamente produtiva.

Mas as convergências e relações possíveis de se estabelecer entre certos aspectos históricos e estruturais da instituição escolar, apontados por Ó (op. cit.), e o tipo de argumentação que levou à inclusão da prevenção às drogas nos currículos escolares, não param por aí. Para o autor, a incorporação de princípios morais, tarefa primordial da escola, principalmente a partir do século XX, encontra nas ideias de "autonomia" e de "liberdade" uma condição fundamental para sua execução (Ó, 2003, p. 112). Ao longo dessa centúria, a imposição violenta de sanções perde espaço para as práticas pedagógicas que supõem o aluno como sujeito livre e autônomo, que deve escolher espontaneamente suas respostas e posicionamentos diante da vida, cabendo à escola dotá-lo do instrumental intelectual que o habilite a conduzir-se livremente. Emerge então a figura do estudante ideal como "aquele que sabe medir as consequências tanto dos seus atos como das formas de comportamento através de regras interiores que resultam das suas experiências pessoais, quer dizer, de uma adaptação espontânea à vida escolar" (idem, ibid.). Também no Fórum de Debates é essa racionalidade, identificada com o liberalismo, que encabeça as proposições de adoção das táticas de prevenção ao uso de drogas como componente dos currículos escolares. Desde o pronunciamento do presidente da Assembleia Legislativa, deputado Octavio Germano, na cerimônia de instalação do evento, quando este afirma tratar-se, ali, de uma "batalha pela Liberdade" (FÓRUM DE DEBATES..., 1971, p. 21), o uso de drogas é apontado como um fenômeno capaz de retirar do indivíduo sua liberdade, justamente aquela que a escola pretende potencializar ao equipar os estudantes de instrumentos que estimulem sua intrínseca capacidade de decidir, autônoma e independentemente, seus caminhos. Do mesmo modo, o secretário de Segurança Pública do Rio Grande do Sul, coronel Jaime Mariath, preocupa-se com a perda da liberdade diante do "vício que domina o cidadão, física e psicologicamente" (idem, ibid., p. 55). Perante uma ameaça extremamente poderosa, capaz de comprometer a liberdade intrínseca ao sujeito, cabe à escola, instituição que fomenta o exercício dessa "faculdade humana", fazendo dela a base para a incorporação de princípios morais fundamentais a esse próprio exercício, desenvolver os mecanismos capazes de dar um freio a tal perigo.

O papel central ocupado pela escola nesse empreendimento de profilaxia social tem, como visto, de um lado, na adaptação e, de outro, na liberdade, condições essenciais a sua efetivação. Na verdade, trata-se de aproximar adaptação e liberdade de tal modo que acabem por confundirem-se uma à outra, de forma a tornar o desejo de adaptar-se à ordem social a vontade espontânea do sujeito, o resultado de sua livre reflexão. A questão central da prevenção às drogas, então, surge como a mesma questão que se tornou central no processo de instrumentalização da educação 
escolarizada como tecnologia de controle social, a saber, a busca por mecanismos de controle que não operem a partir de instâncias exteriores e coativas. Trata-se, portanto, da busca e constituição de mecanismos de controle mais sutis, que não sejam experienciados pelos indivíduos como instâncias de opressão e que, contando com a adesão destes, possam efetivamente produzir a autodisciplina, objetivo último do poder que se dissolve, se desmaterializa e passa a constituir o querer de todos e de cada um, dando vazão à grande utopia estatal e comunitária que tanto ocupou os filósofos políticos da modernidade, de Rousseau a Hegel: a produção de uma vontade geral que, harmonicamente, sedimente uma ordem social equilibrada, orgânica e apta ao desenvolvimento. Uma nação assim constituída poderia, sem dúvida, contar com as forças necessárias à conquista de espaço na política global, erigindo-se numa potência. Reunir e potencializar suas forças, tais os fins do Estado governamentalizado. Aqueles que não quiserem, não puderem ou não souberem se engajar a esse projeto, integrando-se às formas prescritas de socialização, serão considerados "desviantes", responsáveis pelos conflitos sociais, ou, em outras palavras, "criminosos", "deficientes", "loucos", "viciados". Cabe ao Estado e aos corpos de especialistas analisá-los e diagnosticá-los, encaminhando cada individualidade para a instituição adequada a sua normalização. É, portanto, a constituição da educação como profilaxia que faz dela o "lugar" da prevenção ao uso de drogas, lugar de gestão da anormalidade, no qual a adaptação configura o objetivo principal e a liberdade é a condição, o instrumento e o resultado dos processos de adaptação dos sujeitos ao meio social.

A escola, então, como espaço de constituição da liberdade, deve prevenir justamente o uso daquelas substâncias capazes de fragilizar a ação dessa faculdade. É a escola como espaço da razão, empunhando armas para o enfrentamento das drogas que levam à loucura, de forma a garantir o bom cumprimento da missão patriótica da educação: assegurar a cada um a posse de si mesmo. Com base nisso, em 1972, o Programa Educacional Sobre Drogas, elaborado pelo MEC, apontava que se devia "ter sempre em mente que o adolescente pode e deve fazer sua opção; a ele devemos dar os elementos para que possa exercer este seu direito" (MENNA BARRETO, 1976, p. 52). Supunha-se que a prevenção nas escolas simplesmente forneceria as informações sobre drogas para os estudantes, deixando-os livres para fazerem sua opção de usá-las ou não. Como escreve Foucault (1989), a liberdade é condição, é o próprio campo de exercício do poder, cuja eficácia é diretamente proporcional ao nível de consciência que tem o sujeito de estar decidindo por si próprio, sem imposições externas. Desse modo, tentava-se

[...] legitimar uma atuação supostamente imparcial e científica do Estado na educação sobre drogas. Um currículo que deveria ser formado em torno da educação sobre os malefícios já está devidamente direcionado à formação de opinião do aluno. Ademais, que 
opção pode ter uma pessoa que, se pega consumindo ou transportando qualquer droga controlada, é diretamente enquadrado na Lei de Tóxicos, quer seja como doente, quer seja como criminoso. (RODRIGUES, 2004, p. 157)

É possível então, neste ponto, traçar um paralelo, com alguma ressalva, entre uma transformação histórica nos modelos educacionais, ocorrida na primeira metade do século XX, e uma transformação histórica na ênfase do combate às drogas, ocorrida na segunda metade desse mesmo século. Na educação, trata-se da passagem de um modelo autoritário, "essencialmente ligado a fórmulas regulamentares inspiradas diretamente na disciplina militar e de uma lógica de tipo criminal", a um modelo liberal "que agisse sobre o conjunto das inclinações comportamentais e não unicamente sobre o medo" (Ó, 2003, p. 122). No combate às drogas, trata-se da passagem, não plenamente realizada, da ênfase na repressão à ênfase na prevenção. Em ambos os processos é a eficiência do governamento que é visada, a possibilidade de governar mais governando menos. Como afirma René Gonzáles, representante da Organização das Nações Unidas (ONU) no Fórum de Debates, "as medidas de controle, fiscalização e repressão legal são oportunas e necessárias, mas de modo algum se pode esperar que solucionem o problema" (FÓRUM DE DEBATES..., 1971, p. 40), e arremata Luiz Antônio Meira, psicólogo: "existe somente uma grande via de tratamento, que é o tratamento preventivo" (idem, ibid., p. 106). Entende-se aqui que a mesma racionalidade política que faz da escola um espaço de governamento através da liberdade e da vontade também opera uma modificação nas prioridades em relação ao controle do uso de drogas. Embora estas se mantenham proibidas por lei, encontrando-se, ainda, tais práticas no interior de uma lógica de tipo criminal, vem operando-se, a partir da segunda metade do século $X X$, um movimento de abrandamento de penas para usuários, situação que se harmoniza com a visão de que a prevenção constitui tática potencialmente mais eficiente do ponto de vista econômico do que a repressão. ${ }^{5}$

Esses dois movimentos ora referidos são depositários da emergência da racionalidade liberal de governo, que informa um novo modo de gerir a população e os indivíduos em termos econômicos e eficientes. O liberalismo é um tipo de crítica à razão de Estado, "que descobre que governar demais é irracional, pois é antieconômico e frustrante", tratando-se de "um refinamento da arte de governar, em que o governo, para ser mais econômico, torna-se mais delicado e sutil" (VEIGA-NETO, 2002, p. 186). O liberalismo, então, como modo de racionalização do governo, ocupa-se de encontrar a justa medida, o cálculo exato que indique qual a mínima quantidade necessária de poder e de recursos para a consecução dos máximos fins possíveis em termos de condução das condutas. No que tange à adoção de uma ênfase preventiva nas táticas de controle das práticas de uso de drogas, como signo da emergência, também nesse campo, da crítica liberal ao excesso de governo sem 
resultados efetivos, é possível perceber claramente, na análise dos Anais do Fórum de Debates de 1971, o fortalecimento dessa posição, trazida, diversas vezes, por vários dos participantes do evento. Destaque-se, primeiramente, a crítica ao excesso de governo no que se refere ao controle do uso de drogas, enunciada pelo psiquiatra Manoel Antônio de Albuquerque, para o qual:

[...] existindo a droga, não é possível manter uma quarentena permanente, separando-a de virtual usuário. Ambos se buscarão até encontrar-se. Neste particular, o que precisamos evitar é a colaboração da autoridade. Não me refiro, evidentemente, à colaboração dolosa nem consciente. Penso na constatação universal de que o caminho da toxicomania é muito facilitado pelas instituições encarregadas de evitá-lo. Uma prisão, efetivada ou ameaçada, pode jogar um rapaz nas mãos do traficante chantagista. Uma notícia de jornal pode abalar o crédito ou privar do emprego a uma pessoa que não terá outra alternativa senão submeter-se às condições do chantagista que exige sua participação na distribuição da droga. Se o objetivo é prevenir os crimes decorrentes da farmacodependência, precisamos cautela porque alguns preconceitos tendem a aumentar a importância relativa dos tóxicos na causação de delinquência. É verdade que a desinibição que quase todas provocam facilita aos impulsos antissociais encontrarem manifestação. A maioria dos crimes, entretanto, limita-se aos vinculados à obtenção do fármaco. Se excluirmos esses, os índices de criminalidade serão muito pouco superiores à média da população e bem inferiores aos alcoolistas e frequentadores de casas de tavolagem. (FORUM DE DEBATES..., 1971, p. 174)

À consciência, manifestada pelo psiquiatra, da impossibilidade de manutenção de uma vigilância absoluta sobre os indivíduos soma-se a percepção dos malefícios causados pelo governamento demasiado das condutas, os quais acabam, por vezes, a produzir problemas ainda mais graves do que aqueles aos quais se propunham dar solução. Assim, na lógica liberal aqui enunciada, a ineficiência do governo hipertrofiado acaba por minar, em diversos casos, as possibilidades de se incutir o autogoverno, fim último da prevenção. Além disso, Albuquerque (op. cit.) prega uma abordagem técnica e econômica que, desprovida de preconceitos, seja mais eficiente no controle das drogas e seus usuários.

A escola moderna, então, cada vez mais, a partir do triunfo, no mundo ocidental, do republicanismo e do liberalismo, vai centrar sua ação na formação da personalidade, tendo em vista disciplinar e, no limite, fomentar o autodisciplinamento. Encontra-se, aqui, novamente, segundo a racionalidade política do governamento, que gesta a inclusão da prevenção às drogas na educação, a relação antipódica entre escola e uso de drogas: enquanto a primeira dá forma à personalidade, a segunda, para o psiquiatra Clóvis Martins, gera um quadro de "desorganização da personalidade", produzindo "fenômenos de despersonalização", de perda do autocontrole que é "indispensável para os mecanismos de ajustamento da personalidade" (FÓRUM DE DEBATES..., 1971, p. 183, 184-185). Para o psicólogo Luiz Antônio Meira, deve-se considerar os jovens que usam drogas como "portadores de 
uma desarmonia de personalidade" (idem, ibid., p. 105). Os psicoativos, portanto, ao "desorganizarem", "desajustarem" ou "desarmonizarem" a personalidade, esta unidade essencial do "eu" que a escola, com tanto zelo, esculpe, colocam-se como uma séria ameaça à totalidade do projeto liberal-republicano promovido pela escolarização. Assim, é com o intuito de lançar a escola ao enfrentamento direto com o inimigo ameaçador que a prevenção deve ser implementada nessa instituição, para que ela possa juntar-se à

[...] luta permanente [...] que tem por escopo libertar o ser humano dos grilhões do primitivismo, arrancando-o da brutalidade de suas origens das cavernas pré-históricas, para colocá-lo na verdadeira rota que o deverá conduzir ao reino que lhe está destinado, ou seja, àquela dimensão transcendente que hoje apenas intuímos, mas que, amanhã, caso vencedores, nela estaremos perfeitamente integrados, num todo harmônico, bastantes em nós mesmos e saboreando a infinita quietude da realização plena. (FÓRUM DE DEBATES..., 1971, p. 19-20)

Mas como deve a escola lutar essa luta tão épica, que coloca em xeque a liberdade, "a verdadeira rota", e que tem por prêmio a "realização plena"? Apesar da dramaticidade do pronunciamento anterior, feito pelo deputado Octavio Germano, não se trata, em absoluto, do ponto de vista da escola, em 1970, de uma luta nova. Ao contrário, trata-se de uma batalha para a qual essa instituição tem sido sistematicamente convocada, possuindo já certo aparato tático e algumas ferramentas por meio das quais se movimenta no front. Enquanto as instâncias ligadas à segurança pública jogam o jogo da repressão, intentando submeter o adversário pela inoculação do medo, a escola joga o "jogo do pastor", cujo movimento tático se dá no sentido da submissão através da figura do professor, na qual se encarnam a Verdade e o Bem. Ou seja, na atuação histórica da escola se exerce um poder pastoral, cuja efetividade passa por um trabalho no interior do indivíduo e pelo abandono das técnicas repressivas. O conjunto dos alunos, cativados e subjetivados pela Verdade e Bondade, pela correção que emana do mestre, e homogeneizados sob a forma de corpo discente, deseja a condução que é realizada pelo pastor, crendo ser este o melhor caminho. $\mathrm{O}$ exercício desse tipo de poder passa, portanto, necessariamente, pela crença de que há algo significativo e muito importante que está sendo transmitido, ou, em uma formulação mais adaptada à questão da prevenção, que aqui primordialmente interessa, a efetividade desse poder passa pela crença na verdade do que é dito.

A "gramática escolar", assentada em um regime de classes produtor de uniformidade, seguindo um modelo pastoral de condução das condutas e tendo por referência a verdade e a racionalização do tecido social, se apresentava, aos olhos de políticos, administradores públicos, médicos, psiquiatras, psicólogos, homens do direito e da segurança pública, em 1970, quando da realização do Fórum de Debates analisado, como a grande ferramenta capaz de "salvar" a juventude. Junto ao 
salvacionismo pastoral, tratava-se de levar aos estudantes a verdade que a ciência descobria sobre essas substâncias, ou, na formulação do médico Oswald de Andrade, devia-se, "para salvar a geração atual escolar, que vai de 6 a 11 anos, dar a ela as explicações necessárias sobre os perigos das drogas. Esta a maneira de prevenir um risco" (FÓRUM DE DEBATES..., 1971, p. 215). Nesse sentido, parece claro haver uma convergência entre o tipo de política da consciência historicamente instituída pela escola e a lógica de funcionamento da racionalidade preventiva, estando ambas calcadas e diretamente voltadas à autoinspeção e autodisciplina.

Tratava-se, então, de instruir os profissionais docentes acerca dessa nova demanda que o Estado governamentalizado lhes apontava. Tal era, não por acaso, uma das principais metas do Fórum de Debates, que tinha expressamente convidado os docentes de níveis médio e superior a assistirem seus simpósios e conferências, bem como incluído, entre as sugestões encaminhadas a instâncias políticas, médicas e educacionais, a necessidade de adoção de conteúdos de prevenção ao uso de drogas nos currículos escolares. Como disse o deputado Hugo Mardini, ao dar início às atividades,

[...] espero que este fórum seja um momento na consciência nacional, advertindo aos responsáveis pela formação da mocidade que é preciso dar aos adolescentes e jovens brasileiros orientação e compreensão, capaz de dotá-los de discernimento lúcido e adequado acerca dos prejuízos físicos e mentais causados pelo vício em entorpecentes. (FÓRUM DE DEBATES..., 1971, p. 25)

Prevenção às drogas, portanto, como controle do psiquismo e do corpo, elemento central também da "gramática escolar". Para o deputado Octavio Germano, "é em nome das nossas famílias, da pátria e do progresso que devemos levar a cabo essa tarefa [do combate repressivo e preventivo ao uso de drogas]" (idem, ibid., p. 21). Ou seja, o que está em jogo, na luta contra as drogas, é o próprio modo de vida ocidental moderno, calcado na família, na pátria e no progresso. Para que esse modelo de existência social seja possível, é crucial, mais do que impô-lo, fazer com que coincida com os desejos e finalidades dos indivíduos, o que só pode ocorrer se estes forem, desde cedo, devidamente individualizados e homogeneizados, função concernente à instituição escolar. $\mathrm{O}$ uso de drogas, então, surge como ameaça a esse projeto, como um caminho desviante que captura os sujeitos e os instiga a conduzirem-se de outras formas, orientados por outros fins e inclinados a empregarem seus corpos e mentes em atividades diferentes daquelas desejadas pelo Estado, principal fiador do modo de vida moderno. A escola, nesse sentido, emerge como guardiã dos caminhos retos e direitos, em oposição aos comportamentos desviantes que ameaçam a ordem social. A história dessa instituição é a história de uma progressiva busca de encaixe da existência social na lógica governamental, tendo por objetivo fazer com que os sujeitos identifiquem seu prazer com tudo o que puder ser produtivo ao 
Estado para a manutenção dessa específica configuração das relações de poder que atravessam as ordens econômica, política e existencial.

\section{Notas}

1. O pioneirismo desse fórum reside no fato de que foi a primeira ocasião, no Brasil, em que especialistas das áreas médicas e jurídicas, além de autoridades e administradores públicos de diversos órgãos e níveis se reuniram com a comunidade para tratar do tema das drogas. Foram especialmente convidados a assistir esse evento os corpos discente e docente de instituições de ensino de níveis médio e superior, tendo o mesmo dado origem a um documento composto por diversas análises e reivindicações que foram encaminhadas a autoridades políticas, médicas, educacionais, entre outras.

2. "Governamento" é entendido, aqui, seguindo indicações de Veiga-Neto (2002), como a ação de governar, uma ação que se dá de modo a conduzir ou dirigir as ações alheias (ou as próprias). Assim, trata-se de compreender, nesse texto, "governamento" como condução das condutas dos outros e de si mesmo. Não se restringe, portanto, o uso desse termo à condução ou direção do Estado, estendendo-se a uma série de outras instâncias sociais que também são governadas, como a família, os alunos, a população, os indivíduos... O governamento constitui um tipo de poder, uma forma específica de organização e exercício do poder, a qual tem na conduta o seu objeto.

3. A partir deste ponto, os Anais do Fórum de Debates Sobre o Uso e Tráfico de Substâncias Tóxicas ou que Causam Dependência Física ou Psíquica serão mencionados, no texto, como Fórum de Debates.

4. A governamentalização do Estado é entendida, aqui, conforme Foucault (2008), como o processo pelo qual a ação estatal assumiu uma forma governamental, ou seja, o tipo de poder exercido através das instituições estatais assumiu as características da condução das condutas, da gestão econômica e segura dos processos sociais e da fundamentação em saberes voltados à observação e extração, dos objetos a serem governados, dos instrumentos e procedimentos empregados para o seu governamento.

5. Como exemplo desse movimento, é possível referir a descriminalização do uso de drogas consideradas leves, como a maconha, em diversos países europeus, desde a pioneira Holanda, ainda na década de 1970, até os anos de 1990 e 2000, quando Portugal, Espanha e Inglaterra, entre outros, tornaram a posse de pequenas quantidades dessa droga não mais um crime, mas uma infração passível de advertência e/ou penas alternativas. Também o Brasil, no ano de 2006, tomou parte nesse movimento com a edição da Lei n. 11.343, que substituiu as penas de prisão por advertências sobre os efeitos das drogas, prestação de serviços à comunidade e/ou medidas educativas de comparecimento a programas ou cursos preventivos.

\section{Referências}

BRASIL. Lei n. 11.343, de 23 de agosto de 2006. Institui o Sistema Nacional de Políticas Públicas sobre Drogas - Sisnad; prescreve medidas para prevenção do uso indevido, atenção e reinserção social de usuários e dependentes de drogas; estabelece normas para repressão à produção não autorizada e ao tráfico ilícito de drogas; define crimes e dá outras providências. Diário Oficial da União, Brasília, DF, 24 ago. 2006. Disponível em: <http://www.planalto.gov.br/ccivil_03/_ato2004-2006/2006/lei/ 111343.htm>. Acesso em: 7 mar. 2009. 
CHALHOUB, S. Cidade febril: cortiços e epidemias na Corte Imperial. São Paulo: Cia das Letras, 1996.

FÓRUM DE DEBATES SOBRE O USO E O TRÁFICO DE SUBSTÂNCIAS TÓXICAS OU QUE CAUSAM DEPENDENCIA FÍSICA OU PSÍQUICA: sumário dos trabalhos apresentados e discutidos. Porto Alegre: Departamento de Imprensa Oficial do Estado, 1971.

FOUCAULT, M. Vigiar e punir: história da violência nas prisões. Petrópolis: Vozes, 1988.

FOUCAULT, M. Microfísica do poder. Rio de Janeiro: Graal, 1989.

FOUCAULT, M. Segurança, território, população. São Paulo: Martins Fontes, 2008.

MENNA BARRETO, J.D.L. Estudo geral da nova lei de tóxicos. Rio de Janeiro: Rio, 1976.

Ó, J.R. O governo de si mesmo: modernidade pedagógica e encenações disciplinares do aluno liceal (último quartel do século XIX - meados do século XX). Lisboa: Educa, 2003.

Ó, J.R. A maquinaria escolar moderna entre os séculos XVI e XIX: estruturas de uma história do presente. 2008. Trabalho apresentado no Curso de Extensão "A Maquinaria Escolar Moderna Entre os Séculos XVI e XIX: estruturas de uma história do presente", São Leopoldo, 2008. 26p.

ORTIZ, R. Cultura brasileira e identidade nacional. São Paulo: Brasiliense, 1986.

RODRIGUES, T. Política e drogas nas Américas. São Paulo: Educ; Fapesp, 2004.

VARELA, J.; ALVAREZ-URIA, F. Arqueología de la escuela. Madrid: La Piqueta, 1991.

VEIGA-NETO, A. Coisas do governo... In: RAGO, M.; ORLANDI, L.B.L.; VEIGANETO, A. (Org.). Imagens de Foucault e Deleuze: ressonâncias nietzschianas. Rio de Janeiro: DP\&A, 2002. p. 13-34.

Recebido em 8 de abril de 2012.

Aprovado em 26 de março de 2013. 